\title{
FEATURES OF ENTERPRISE DEVELOPMENT MANAGEMENT BY INDICATORS OF IMBALANCES
}

\author{
Oleksandr Likhota ${ }^{1}$
}

\begin{abstract}
The paper considers the model of enterprise development management taking into account imbalances, which allows to improve its quality in the short and long term. It is proved that the development and operation of special management functions, the implementation of strategies in the proposed set of measures improves the quality of management in terms of imbalance in the direction of achieving or maintaining the development of the enterprise. It is shown that in order to prevent the risk of losses from imbalances it is necessary to use monitoring, which will identify factors of economic imbalance of enterprise development indicators and identify trends, and the result of its use is to take into account early signals and ensure timely implementation of enterprise development strategy. Attention is drawn to the fact that the system of diagnostics of imbalances is characterized by various objects and subjects involved in this process, and its object is a complex highly organized dynamic system and its elements. Such work on the diagnosis of imbalances should be carried out by the analytical services of the enterprise, and in the absence of specialists with sufficient knowledge and experience it is possible to purchase analytical services in consulting firms. Attention is drawn to the fact that the initial stages of the technology of management decisions are the development of a system of measures, collection of initial information about the situation in the company, morphological analysis of external and internal environment, search for options to avoid imbalances. In order to assess the possibility of implementing strategic directions, it is necessary to distribute them according to the level of priority, adequacy of resource potential, lack of funds, which becomes an incentive to increase the economic stability of the production enterprise. Management actions to prevent imbalances in corporate governance should be carried out at the expense of internal resource potential, and depending on the availability of resource and management capabilities, the following types can be used: management: organization; consulting management; crisis management.
\end{abstract}

Key words: consensus, compromise, imbalance, vertically integrated corporate structures, enterprise development indicators, special management functions, control algorithm.

JEL Classification: G32, H12

\section{Introduction}

Relevance of the research topic is connected with the fact that the development of Ukraine's economy in the crisis is characterized by frequent and sharp changes in trends, lack of regularity and sustainable development. In real life, this state of affairs can be characterized as the presence of systemic imbalances, when the characteristics of some elements of the economic system do not meet the needs of others. In parallel, features of management of development of the enterprise by indicators of imbalances allow to justify elements and functions of the corresponding management system, methods of its effective application in practice. In such conditions, it is necessary to determine the degree of compliance of the theory with the needs of the practice of enterprise development management, to form requirements for a set of methods and tools for diagnosing imbalances and to create conceptual provisions for enterprise development management.

Analysis of publications shows that this problem is given considerable attention in the works of B.M. Andrushkiv, Yu.P. Anisimov, A.V. Glazunov, E.L. Smolianov, E.M. Korotkov, T.V. Hrynko, S.V. Koverh, N.V. Kasianova, V.L. Tovazhnianskyi, O.Yu. Tolkachenko, I.M. Dli, O.S. Masyutin, S.V. Shaposhnikov, M. Robson, B. Colasse, J.L. Gibson, F. Ullah. Despite the availability of these studies, the issue of enterprise development

\footnotetext{
Corresponding author:

${ }^{1}$ Donetsk Institute of Private Joint-Stock Company "Higher education institution

"Interregional Academy of Personnel Management", Ukraine.
} 
management by indicators of imbalances needs to be systematized and further studied.

The purpose of the work is a study of the peculiarities of enterprise development management by indicators of imbalances.

\section{Research materials}

It is necessary to start the presentation of research materials with the fact that in the current conditions of Ukraine there is a significant number of imbalances associated with the needs of enterprises in the workforce, the mismatch of their products to market needs, difficulties in finding investment funds. In such circumstances, enterprises are forced to work in conditions of systemic imbalances, which are superimposed on microimbalances in their internal structure. On this basis, when choosing a technology to manage the company there is a need to take into account the nature of existing problems (standard, typical or non-standard) and determine the features of management. First of all, we consider the features of management depending on the level of balance of the enterprise: consensus; compromise; imbalance.

In condition of consensus, management is focused on identifying negative trends. In this case, emphasis should be placed on a preventive management model based on a diagnostic checklist. This model is aimed at anticipating the response to critical factors of imbalances and the formation of a program of preventive action. In the course of such actions, the diagnosis of latent signals of threats to the company's development is carried out. The imbalance of the system is often preceded by signals, the analysis of which allows to establish the nature of the problems, which makes these actions very important.

In conditions of economic disequilibrium (compromise), there are tendencies of increase of tension at the enterprise. In such circumstances, a model is needed to balance the interests of the company and all stakeholders. This model reveals ways to increase the economic balance of the corporate structure. Depending on the sufficiency of own potential, the range of measures to regulate imbalance factors is determined. On the basis of regulatory measures the consistent mitigation of acute problems with the subsequent change of a direction of influence of negative factors is provided. In the absence of effective measures, there are uncontrolled trends that lead the company to deepen imbalance.
Most specifically, the need to manage the development of enterprises in terms of imbalances is manifested in the crisis period (imbalance). During this period, a set of measures is needed to identify the objects of imbalances, assess their consequences, establish points of imbalances and factors of their change, to carry out regulatory measures. The result of regulatory measures is a gradual increase in the balance of economic development of the corporate structure.

One of the main elements of enterprise development management is the diagnosis of their economic situation. As indicated by E.M. Korotkov, diagnostics provides a definition of the state of an object, subject, phenomenon or process through the implementation of a set of research procedures, identifying weaknesses and bottlenecks. Diagnosis is not the one-time act, but a process that is carried out in time and space with the participation of specialists with a high level of qualification (Korotkov, 1997).

In the process of diagnosing enterprises, various tasks are solved. Firstly, one of the important tasks solved by controlling, according to B. Colasse, is the observation of processes occurring in real time, comparing the target results with the achieved ones (Colasse, 1997). This position emphasizes the importance of monitoring in the rapid detection of imbalances, but does not take into account the strategic manifestation of the imbalance of enterprise development processes.

Secondly, in order to prevent the risks oflosses from imbalances, monitoring is needed to allow to identify the factors of economic imbalance of indicators of enterprise development in time and to establish trends in their changes. The result of monitoring of negative factors and trends is to take into account the early signals and ensure the timely implementation of the strategy of enterprise development management in the context of imbalances.

Thirdly, in the process of diagnosing imbalances in enterprise development, it is important to ensure the effectiveness of the information retrieval system. When diagnosing imbalances, not only the static condition of the object is investigated, but also its development over time. The information is grouped in two directions:

a) the influence of factors that stabilize the system;

b) the dynamic properties of the system and the scale of their manifestation.

Fourthly, in regulating imbalances, it is necessary to use monitoring as a tool to control the impact 
of sectoral and territorial environment on the company's activities. During the monitoring it is necessary to identify and assess the impact on the end result of controlled and uncontrolled factors.

Fifthly, in conditions of increasing imbalance of sectoral and territorial environment, the monitoring system should be as viable and useful as possible, have an innovative character from the standpoint of implementing the latest management methods and advanced technological processes.

The system of diagnostics of imbalances is characterized by various objects and subjects that participate in the diagnostic process. The objects of diagnosis are both a complex highly organized dynamic system and any element of this system, which should be represented from the standpoint of stakeholders. As O.V. Glazunov points out, stakeholders in the diagnosis may be the owners of enterprises, their contractors, banks, tax authorities and others (Glazunov). Practical work on the diagnosis of imbalances should be carried out by the analytical services of the enterprise, but specialists may not have sufficient knowledge and experience to conduct diagnostic procedures. In such cases, it is possible to purchase analytical services in consulting firms. Retraining and raising knowledge of the specialists of the production organization provides more accessible opportunities.

The initial stages of the technology of management decisions are the development of a system of measures, the collection of initial information about the situation in the company, morphological analysis of the external and internal environment, the search for options to avoid imbalances. In this sense, the technology of management decisions is narrow and should be presented as an active process of movement of the company from the priorities to obtain the planned results in management. On the basis of the chosen priorities, options of their realization, which become a basis of directions of development of the enterprise, are defined. For the formation of such options and the program of their implementation, barriers to sustainable development should be established. To create development programs, it is necessary to identify factors that influence the causes of negative trends. Given the influence of such factors, the strategic directions of development of enterprises of vertically integrated corporate structure are determined.

Assessing the possibility of implementing strategic directions, they are distributed according to the level of priority, the adequacy of resource potential is considered, and if there is a lack of funds, they are reviewed. As N.V. Kasyanov points out, the implementation of these areas becomes an incentive to increase the economic stability of the production enterprise and makes it possible to avoid imbalances at the macro and micro levels (Kasyanova, 2014).

Management actions to prevent imbalances in corporate governance should be carried out at the expense of internal resource potential. Depending on the availability of resources and management capabilities in solving problems, the following types can be used: organization; consulting management; crisis management. The organization is carried out by the company's specialists while improving the effectiveness of interaction between its employees. This type involves the use of the resource potential of the corporation in order to carry out independent measures to reduce the risk of losses from imbalances. The application of organization model largely depends on the competence of management. Most often, in the management of the corporation there are specialists who have the necessary competencies, but managers may not have such competencies, which reduces the effectiveness of the measures taken. In many cases, as imbalances increase, owners reduce control over the actions of managers, which can also pose an additional risk of making erroneous measures in making appropriate management decisions. Thus, in order to form a development strategy that allows to balance the goals of all stakeholders, at the first stage it is necessary to identify development priorities for each of the enterprises that are part of the vertically integrated corporate structure (VICS).

At the second stage the competitive position of the enterprise in the market is defined, i.e. the degree of performance of the revealed requirements of interested parties at the enterprise and at competitors is compared. When conducting periodic tracking of changes and constructions of "profiles" of your company and competitors, you can get very useful information, the analysis of which will give an interpretation of tactical and strategic actions of competitors.

The third stage is related to the definition of the relationship between the requirements of stakeholders and indicators of enterprise development, as well as the establishment of mutual correlation between indicators of enterprise 
development, which allows to take into account their impact on each other. It should be noted that when calculating and controlling development indicators, managers forget about such a category as the quality of management, which plays an important role in the successful development of the enterprise. Based on the above, it is advisable to divide all indicators into two groups: indicators of management quality, which characterize the level of development tools and methods of management as a whole, and its individual units and indicators of organizational development, which characterize the level of corporate structure and its units.

At the fourth stage, the final list of indicators of enterprise development is determined and their planned values are calculated. Based on the obtained actual values of development indicators and their planned values, an enterprise development strategy is created, which has the following advantages: the strategy will take into account the requirements of all stakeholders; will take into account the impact of various development indicators on the implementation of these requirements; meeting the requirements of stakeholders will be correlated with the current competitive position of the enterprise; the influence of development indicators on each other will be taken into account, which will allow to avoid mistakes in the planning, when, for example, the necessary increase of one indicator leads to an undesirable decrease of another; strategic decisionmaking will be more reasonable, as it will be based on quantitative data obtained by calculation.

In case of a further increase in the imbalances in the development of the enterprises of a vertically integrated company, it becomes necessary to manage taking into account a number of priority measures:

- information on the occurrence of imbalances should not be share outside the corporate structure; - the control over the factors provoking imbalances is provided from the moment of their occurrence; - development management taking into account imbalances justifies the need to preserve and restore the economic activity of the main enterprises of the technological chain.

For realization of the specified directions, the scheme of management of development of the enterprises of corporate structure taking into account imbalances is presented (Figure 1). The developed algorithm for managing the development of the enterprise on the indicators of imbalance contains four main stages, which involve the use of appropriate mathematical methods: regression analysis; comprehensive operational assessment; risk analysis of losses from imbalances; assessment of the effectiveness of the management mechanism of enterprise development by indicators of imbalance.

This stage of the study must be completed by assessing the economic effectiveness of the proposed algorithm for managing the development of the enterprise by the indicators of imbalance of development factors and with the help of special management functions.

In order to solve this problem it is necessary to consider the concept of economic effectiveness of the process and the mechanism of development management by the indicators of imbalance. Several approaches to defining the nature and essence of the concepts of quality and effectiveness of management are proposed. Comparing indicators of quality and effectiveness of the process of functioning of the system as factors of structural analysis, some approaches determine its structure in the magnitude relation "causes - results", and another determine the algorithm for converting resources into results. Quality indicators are evaluated by comparing the homogeneous characteristics of the properties of the object, actual and target indicators. In this case, the effectiveness should take into account various indicators of results (system outputs) and resources (inputs), which characterize the usefulness of the results of their consumption.

A well-known specialist J. Gibson believes that the concept of effectiveness should be based on a temporal model of organizational effectiveness (Gibson, 2000). The scientist emphasizes organizational effectiveness as the ratio of the results of its activities to the costs used for these resources-factors. Moreover, short-term results can be the increased sales, reduced losses, costs and more. To the list of internal (individual and group) effectiveness factors in the short term, J. Gibson includes quality of work, flexibility of reactions, staff satisfaction, and in the long run - taking into account external opportunities and environmental threats. In the author's opinion, the effectiveness of assessing the quality of management of economic processes should be defined as a measure of the result from the standpoint of efforts spent to achieve it. Evaluation of indicators of the level of balance, quality indices and performance of special functions of development management 


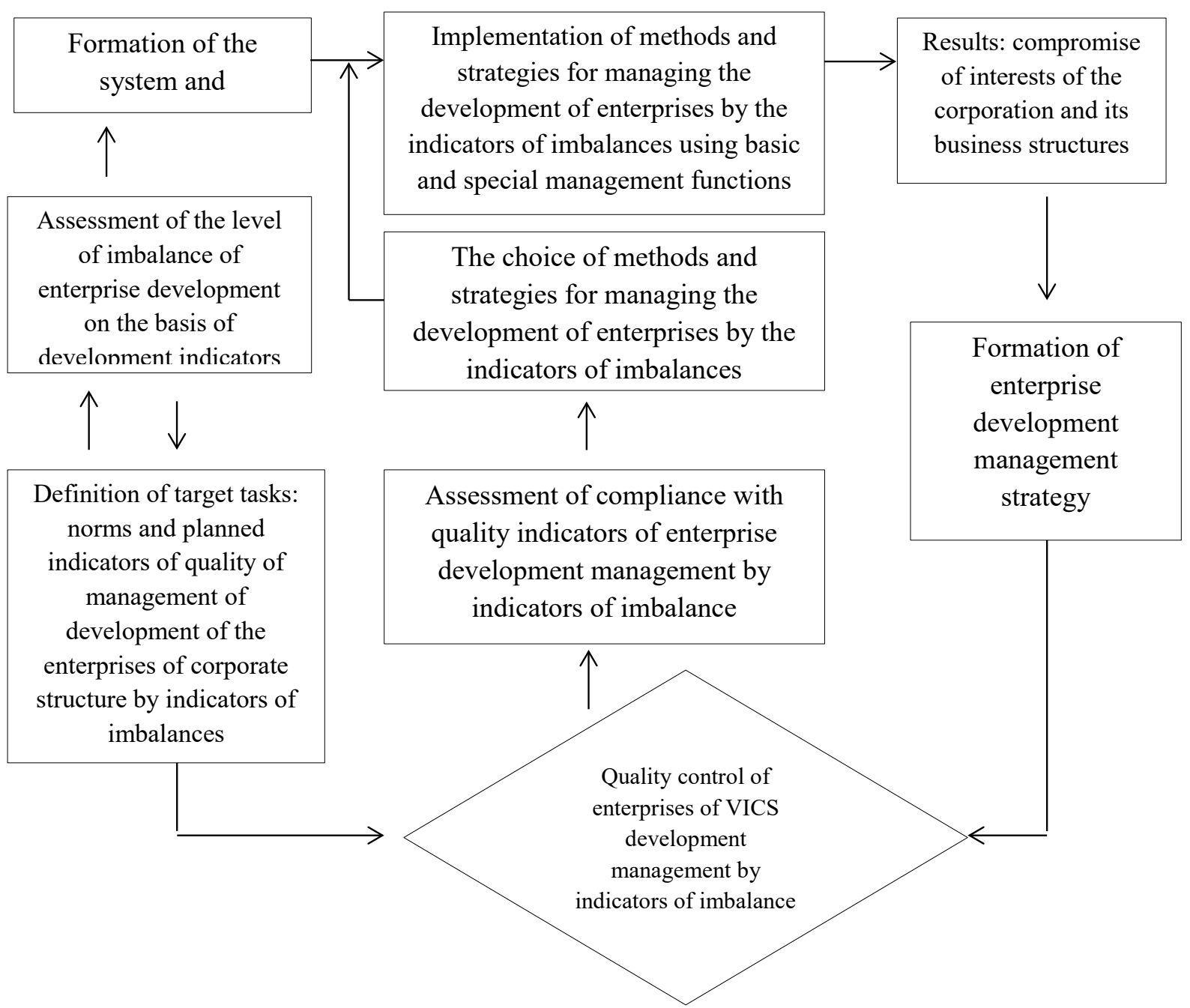

Figure 1. Decision-making on the regulation of imbalances

by indicators of imbalance, characterizes the complexity of this system. The gradual process of increasing economic effectiveness is carried out using the established algorithm and special control functions that reduce the level of imbalance and reduce the economic risks of losses from imbalances. Thus, the application of this algorithm and management functions makes it possible to regulate the imbalance in the development of enterprises and, consequently, increase economic effectiveness in the process of reducing risk losses

$$
\sum_{i} \sum_{j} V D_{i j} \rightarrow \text { min. }
$$

The criterion for minimizing losses from imbalances is the minimum of integrated mathematical expectation of losses from risks of imbalance. This provides a minimal integrated mathematical expectation of losses. Analytical representation of the integrated mathematical expectation of losses from imbalances is a simple arithmetic sum of the mathematical expectation of all types of losses.

\section{Conclusions}

As a result of the study, the following conclusions can be done:

1. Management of enterprise development taking into account imbalances allows to improve the quality of development management in the short and long term, which is expressed in an integrated indicator of the level of balance in the range of "compromise - consensus".

2. To reduce economic losses from delayed response to the regulation of imbalances in enterprise development; to assess the economic losses resulting from the occurrence of a risky event due to an imbalance; to take measures to reduce imbalances in the development of the enterprise through appropriate strategies. 
3. Development and operation of special management functions, implementation of strategies in the proposed set of measures improves the quality of management in terms of imbalance in the direction of achieving or maintaining the development of the enterprise.
These provisions characterize the management system of a vertically integrated corporate structure with the simultaneous provision of values and motives, attitudes and threats, the definition of conditions that may be a motive or barrier to productive work.

\section{References:}

Korotkov, E. M. (1997). The concept of management. Moskow: Deka, 304 p.

Colasse, B. (1997). Management of financial activities of the enterprise: Problems, concepts and methods. Translated from French. Moskow: Finance: UNITI, 575 p.

Glazunov, A. V. Balance of interests of stakeholders. Available at: http://quality.eup.ru/DOCUM6/ balans-interesov-zainteresovannyh-storon.htm

Kasyanova, N. V. (2014). Assessment of the balance of enterprise development potential. Management models in a market economy: Coll. Science. Donetsk: DonNU, pp. 62-73.

Gibson, J. L. (2000). Organizations: behavior, structure, processes. Translated from English. 8th ed. Moskow: INFRA-M, XXVI, $662 \mathrm{p}$. 